\title{
Gamification in a Social Learning Environment
}

\author{
David Giannetto, Joseph Chao, and Anthony Fontana \\ Bowling Green State University, Bowling Green, OH, USA
}

\author{
dgianne@falcon.bgsu.edu, jchao@bgsu.edu, afontan@bgsu.edu
}

\begin{abstract}
Gamification has gained traction in recent years as an effective way of engaging users to perform actions in contexts that would otherwise be considered tedious and undesirable. Education is an area in which user engagement could have the greatest impact on success, with some advantages for students being improved grades or better comprehension. The authors of this paper have designed and implemented a three part system for gamifying a social learning environment designed for use in higher educ ation lecture classrooms. Our goal in doing so is to foster greater user engagement from the students using the system and thereby promote an environment better suited for active learning.
\end{abstract}

Keywords: QizBox, Gamification, Online Learning, Engagement, Software Development, Education, Social Learning Environment.

\section{Introduction}

The definition of gamification that is most widely accepted across the industry, as described by Deterding et al. (2011), defines gamification as "the use of game design elements in non-game contexts." The word Gamification, as pointed out by Fabian Groh (2012), while first being coined earlier in the 2000's, did not gain recognition from a wider audience until late 2010. UserEngagement is the key goal of all gamification; therefore, it is also important to examine what user engagement is, and what positive effects that increasing engagement can have. O'Brien and Toms (2008), explained this idea by offering a definition of engagement as consisting of users' activities, attitudes, goals, mental models, and motor skills. This definition encompasses not only the physical aspects of a user's interaction with a system, but the mental aspects, as well. They go on to explain how engagement manifests itself in the form of attention, intrinsic interest, curiosity, and motivation. One area where all of these qualities are clearly beneficial is the area of education.

QizBox is a social learning environment designed to increase active learning in a lecture or discussion classroom setting. Developed over several years at Bowling Green State University, the system allows students attending a face-to-face lecture to log in, using any web browser, and par-

Material published as part of this publication, either on-line or in print, is copyrighted by the Informing Science Institute. Permission to make digital or paper copy of part or all of these works for personal or classroom use is granted without fee provided that the copies are not made or distributed for profit or commercial advantage AND that copies 1) bear this notice in full and 2) give the full citation on the first page. It is permissible to abstract these works so long as credit is given. To copy in all other cases or to republish or to post on a server or to redistribute to lists requires specific permission and payment of a fee. Contact Publisher@InformingScience.org to request redistribution permission. ticipate in the lecture through an interactive online setting (see Figure 1). The in-lecture design consists of a live slideshow of the lecturers' presentation slides synced across all browsers. Next to the slides, multiple tabs provide a textual chat room, an area for questions and threaded answers (posted anonymously if chosen), and an area to take notes directly related to each slide. Another feature allows the presenter to pop up 
quiz questions that are recorded, stored, and presentable in real-time graphs. The system also archives all activity that takes place in the lecture and allows users to review it later at their convenience. To further engage users of this system, we have designed and implemented an award system based on achieving the most well-rounded and complete user engagement possible while not affecting the usability of the system.

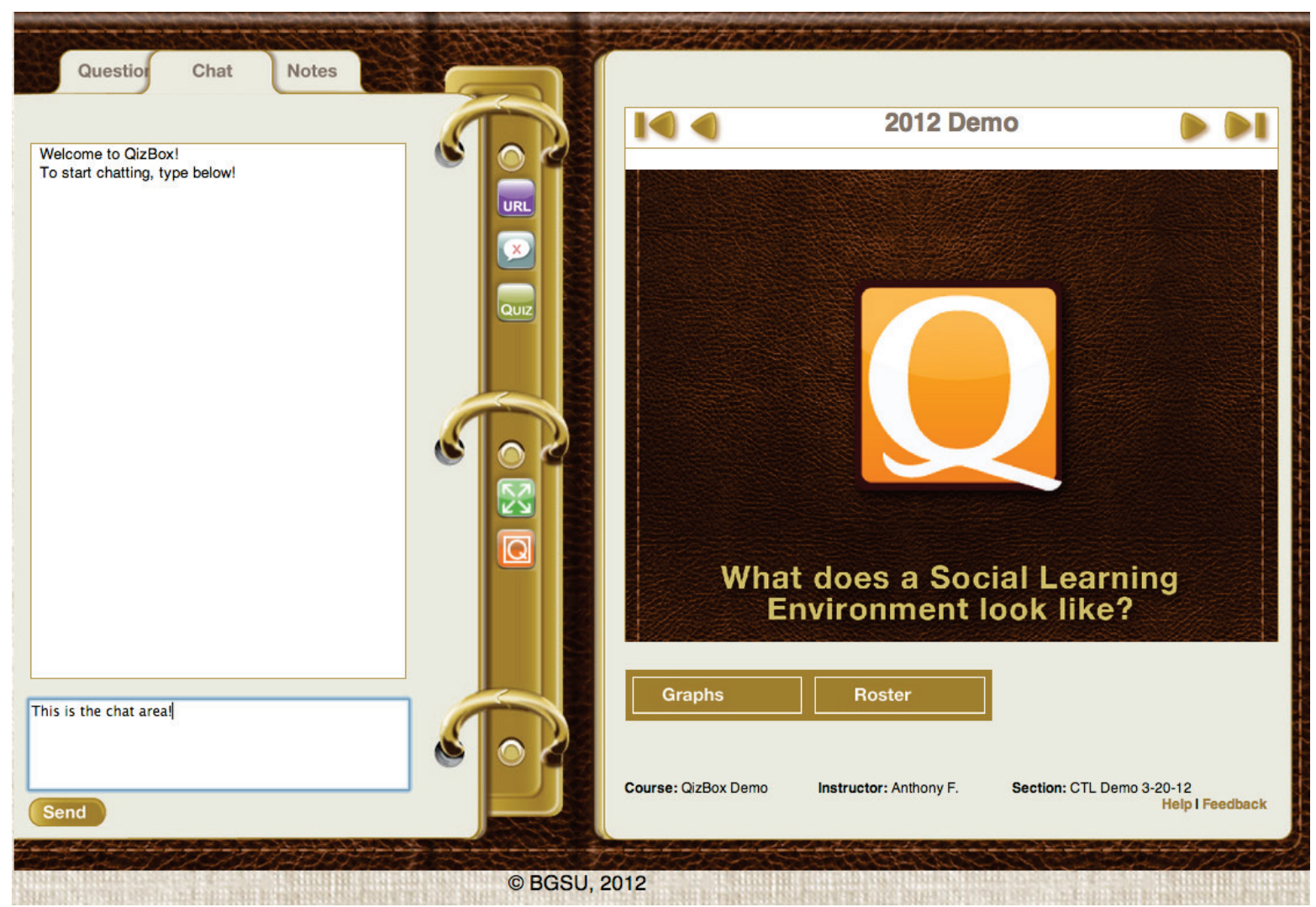

Figure 1. QizBox in-lecture design

To do this, we first took a look at gamification itself, what methods are being used, and how these methods are being implemented. We then examined QizBox as a system and how the design of the system itself will affect what methods of gamification we use. Finally, we discuss the implementation of our new system, the current state of our research, and what is planned for the future. Through the use of gamification techniques, our goal is to increase user engagement in the system, and by association, increase a student's engagement in their learning.

\section{Motivation}

It is widely accepted that if a student is engaged in his or her learning and demonstrates the qualities that engagement manifests, he or she will be a successful student. Edwin Locke's comparison of goal-setting theory and control theory adds a very important notion to this idea (Locke, 1991), that goal oriented approaches to work are historically found to encourage human engagement in what tasks would otherwise be considered by many to be unpleasant and undesirable to perform, and that there are decades worth of evidence to support this fact (Locke, 1991). Gamification strives to utilize this goal-oriented approach to achieve engagement. It is also clear that engagement in education is a desirable result to strive for, and one that can provide a number of benefits. As Lee and Hammer point out (2010), the education system today faces major problems around student motivation and engagement. 
It is unquestionable that games have amazing motivational power. During a 2010 TED talk, Jane McGonigal, author of "Reality Is Broken: Why Games Make Us Better and How They Can Change the World," pointed out that from the time of its creation through 2010, players of the popular online game World of Warcraft have spent a total of 5.93 million years in the game's online environment (McGonigal, 2010). That figure shows the astonishing motivational power that a well-designed game can have, and as Lee and Hammer go on to point out, with future advances in technology, gamification is going to be a fixture in students' lives for many years to come. If through research and development of new systems, we can harness the motivation power of these techniques and direct it toward learning, we can help students acquire the tools to become higher achievers in real life, (Lee \& Hammer, 2010) and this fact, as McGonigal (2010) points out, will lead to greater advancements for humanity as a whole. As software engineers, creating a system that will have a truly positive effect on the world is something we strive for. It is our hope that research in this area will help to achieve that.

\section{Gamification in Depth}

\section{Definition}

To fully understand gamification, it is important to examine the definition more closely. First of all, as Deterding et al. (2011) are clear to point out, gamification relates to games, not the more broad term of 'play.' The difference in the two terms being that games are specialized systems that are characterized by explicit rules and the attempt within those systems to achieve certain goals or outcomes. Play, on the other hand is a term that refers to a much broader and free form type of activity.

It is also valuable to examine what exactly is meant by the term 'element'. As Groh (2012) states, in contrast to 'serious games' which are full-fledged systems, gamification refers to the use of only specific elements of game systems. These elements, when combined with the idea of 'design' are also referred to as game mechanics. It is this idea of design that distinguishes game mechanics from the other elements of gaming - those being game technology, and game practices (Deterding, et al., 2011). However, as Miguel Sicart (2008) shows, even with that in mind, the meaning of the term 'game mechanics' is not something that is necessarily straightforward. Magne Gåsland (2011), of the Norwegian University of Science and Technology, defines a game mechanic as "An element of a game that is made up of a set of rules and feedback loops used to incentivize the player." This definition does a great job of pointing out the incentive value of game mechanics. This also underscores why gamification is gaining popularity in the design of systems of work or tools for learning. He goes on to provide many examples of game mechanics, which range from items, points, and levels, to appointment and bonuses. As made apparent by these examples, game mechanics can refer to a vast range of elements found in many different games.

\section{Usage}

When examining the ways in which gamification is used, it is first important to examine what is meant by 'non-game contexts.' While there is some debate on what exactly that means, as Deterding and Groh both state, it is reasonable to assume that the prevalent expected use of games is, primarily, entertainment (Deterding, et al., 2011; Groh, 2012). Therefore, for our purposes, we can define a non-game context as any context with an expected use other than simple entertainment. In our case, the goal is to facilitate a student's engagement in their classroom learning experience. Another facet of this idea that needs to be examined is what types of mechanics are there that might be used in gamification. 
There are dozens of different mechanics found in games that can be applied to gamifying other applications (Gåsland, 2011). We will consider some of the most popular ones, starting with ingame items that are given to players of games and serve one of two purposes. One purpose for in-game items is to make a character stronger and allow them to progress through the game more easily. The other purpose of items is simply to act as a trophy of a particular goal that a player has reached. When an item has the latter purpose, it acts similarly to another type of mechanic, that being an achievement. Achievements, also referred to as badges, are given to players who have performed a particular action or actions. Achievements act as a way of providing positive feedback and rewards to a player for performing the tasks desired of them by the system. They also, however, act as a means for a player to show their accomplishments off to other players in that game. Another very popular mechanic in games is a point based level progression system. This type of system is based on players gaining points for performing in-game tasks and then gaining levels based on the points they have gained. This allows player to feel a sense of progression through the game as a gradual pace based on their amount of action in the game. One thing all of these mechanics have in common is that they revolve around some goal or objective.

As Rick Raymer (2011) shows, understanding the structure of the goals you are setting in a system is key to the design of the system. There are two basic structures to goal progression; linear and non-linear. Linear goal progression is rather simple and used to at least some extent in almost all games. It involves organizing goals in a fashion that they must be completed in a specific order and one must be completed prior to moving on to the next. This is a very logical and common practice in games. As a game designer, you would not want a player to enter the game, and immediately beat the final level without having to progress through any other goals or objectives first. It is much more logical to have a player have to go through lower levels and increase their skill incrementally before beating the game. Although some would argue that this method leads to predictable and constrictive gameplay, it allows for goals and objectives to be organized in a way that will make the most sense for any potential user.

The other basic structure of goal progression is non-linear. This is characterized by letting players choose how they proceed through the game. In contrast with linear progression, this allows for users to do different goals and objectives as they deem necessary. Although it can lead the user to a higher feeling of freedom within the system, it can also lead to gameplay that is disjointed and does not flow well. However, a designer can combat this by providing easy, natural feeling connections between certain goals and objectives, and making other transitions more difficult. This will allow a player to advance in a way that fosters a feeling of freedom within the system, but in a fashion that mimics a linear structure. Once you understand the mechanics involved, and the structure that the mechanics will be following, the last consideration is how best to use the mechanics to achieve the desired outcome.

Sebastian Deterding and Amy Jo Kim, two leading minds in the realm of gamification, both discuss methods of properly using the ideas of gamification to best engage your audience (Deterding, 2011; Kim, 2011). Deterding begins by separating the idea of gamification into three separate categories; meaning, mastery, and autonomy. Kim also mentions these three ideas as being the key goals to a well-gamified system. To achieve meaning, as Kim points out, it is important to understand your users, know what drives them, and to use the game mechanics to encourage positive emotions and relate the system to them in some personal manner. Mastery, as Deterding states, is where the fun of games really comes from, the idea the user has of accomplishing interesting and appropriately difficult challenges, and the corresponding positive feedback, encourages users and gives them a feeling of accomplishment. This is what fosters the feeling of fun. Deterding goes on to point out that autonomy might be the most important of these three ideas, in that if a user does not feel autonomous in his actions, then it leads to a feeling of being forced to perform a task which, no matter how fun or engaging an action might be intrinsically, if a user 
believes they are being forced to do it, they are far less likely to enjoy performing that particular task. Deterding and Kim both agree that gamification is best achieved by considering these ideas, and using game mechanics to light the way to achieving them.

\section{Examples}

Examples of gamification are found now, throughout many different areas, especially since the explosion of mobile application technology. Zicherman and Cunningham (2011), in the book Gamification by Design, examine a number of examples, the most popular of which are arguably the breakout mobile applications Foursquare and Nike Plus. Foursquare uses game mechanics such as badges and leaderboards to encourage users to visit different places and report what places they do visit. As Zicherman and Cunningham point out, Foursquare was born from the ashes of "Dodgeball," an application that had almost the same functionality, but was unable to keep a user base engaged their product without Foursquare's core concepts of points, levels, badges, and leaderboards (Zichermann \& Cunningham, 2011). This evolution serves as an important study on the power of gamification. Nike Plus, on the other hand, uses game mechanics such as social support, metric tracking, and 'juicy' feedback to encourage users to push themselves to run farther and faster as a method of getting and staying in good physical condition. Its clever uses of game mechanics allow it to be adaptable for beginners and expert runners alike. These are both excellent examples of gamification, and do a good job of meeting the criteria of meaning, mastery, and autonomy by giving their users a method of tracking their progress, comparing themselves to other users, supplying positive feedback when certain milestones are reached, and providing a platform for users to maintain a feeling of autonomy.

Gamification examples are not, however, limited to the world of mass market mobile applications. One such example from outside that realm is provided by Markus Montola et al. who provide research about using achievement systems to enhance user experience in a photo sharing service (Montola, et al., 2009). While they documented a variety of responses from users of the system, it is clear from their research that a noticeable percentage of users appreciated the added gamification and found their user experience improved, and found themselves more engaged by the effects of the added system. Another such example comes from Ran Cheng and Julita Vassileva (2005), who developed an adaptive reward mechanism for an online learning community. Their research revolved around a dynamic rating system to evaluate posts, and a virtual currency system in coordination with the ratings. The case study compared two groups, one using the currency system, and one using the rating system with no currency earning involved, both groups consisting of fourth year college students. The evidence shows that there is a definite increase in user engagement in the group with the added currency system, evidence that goes to show that gamification can certainly increase engagement, even within college students, when applied properly, a fact that is extremely worthwhile to note for our particular project. It is important for us to examine all of these examples, why they work, and how we can use that information to inspire and influence how QizBox is gamified.

\section{QizBox}

\section{Overview}

The most important part of designing a system of gamification is to understand the application being modified or enhanced and the expected behaviors of the users in that system. QizBox is a web application developed at Bowling Green State University (BGSU). Designed by Anthony Fontana and developed by students under the guidance of Dr. Joseph Chao, it is currently used in over a dozen classes by hundreds of students across multiple fields of study. 
QizBox started as a BGSU Information Technology Services sponsored project for students in the university's software engineering class to develop and implement (Chao, Parker, \& Fontana, 2011). The aim from the beginning of the process was to provide a learning environment that encourages social engagement from the students. The system is designed to, not only allow students to attend a lecture and participate as they normally would, but also allow students to add a social and collaborative experience to the lecture. To understand a user's actions in a lecture on QizBox, it is important to understand how the program works.

The process of attending a lecture in QizBox begins with a presenter creating a course and, within that course, a lecture. A presenter has the ability to upload a presentation, change lecture settings, and create quiz questions to be asked during the lecture. The presenter can also add students to the roster for a class. Rosters are organized by section, and there can be multiple sections per course. Furthermore, because users can log into QizBox via a secure LDAP university account, QizBox specific account, or Facebook account, a presenter has the ability to limit what types of users can attend their lecture. Because class rosters would only contain university students, rosters are limited to university logins.

If a student logs onto QizBox and they are in the roster for an active lecture, they are able to see the lecture on a user dashboard. One click from the dashboard will take them directly to the lecture page. Alternatively, if the roster has not been set up, or if a user wants to attend a lecture as a guest, the presenter can display a url on a presentation screen visible in the lecture hall. A user may type that url into their browser and be taken directly to the lecture page. Upon arriving at the lecture page, the user will see the lecturer's slides on the right hand side of the interface and a chat room on the left hand side. Depending upon the settings previously chosen by the presenter, the student's slides can either be synced with the presenter's presentation, or the student can be allowed to freely traverse the slideshow. The left hand side of the page can be switched between the chat room, an area to ask and answer questions, and the notes area. This allows for a student to have all of the functionality readily available to them depending upon their needs that particular moment.

\section{Features}

The chat room is an area for students to openly discuss the content being presented in class. It is a feature that is vital to the interactive social learning that QizBox strives to provide. It provides a place for students to discuss their own thoughts of the subject matter while also hearing other points of view. Presenters also have access to the chat room allowing them to moderate the chat while occasionally providing their own insights to the students, as well. The presenter has the ability to turn the chatroom on or off during a lecture, thereby directing the attention of the students. Various strategies for managing this chatroom have been developed by faculty using the system.

The questions area is a place for students, or presenters, to ask questions about the subject matter. There are three key features to the question area. The first of these features is that users can provide answers that are linked with specific questions. This allows for multiple questions to be answered at the same time with no confusion as to which question the answer is meant for. This is done by threading the answer below each question. The second, and perhaps more important feature of this, is the ability for students to ask questions anonymously. This anonymity is something that is impossible in a conventional classroom. Many students have questions that they believe are too 'dumb' to ask in front of other students, and, therefore, those questions often go unasked. By providing a method for students to ask questions without fear, and by allowing other students to answer them instead of the presenter taking the time to do so, the learning potential for the lecture is greatly increased. The last feature in this area allows each individual question or 
answer to be ranked up or down by users. Taking advantage of this feature, important questions or answers are ranked upwards, signifying their importance.

The notes section allows students to take notes directly related to each of the presenter's slides. A student can simply click on the notes tab, choose the appropriate slide from the list that appears, and type the desired notes. These notes are stored in the system and available to be viewed in the lecture or from the user profile at a later time. Notes may also be shared by email or with the click of a button, with other students from the same lecture within the system, or downloaded. Sharing notes within the system allows for greater collaboration between students.

At any time during the lecture, a presenter may choose to launch a quiz question to the students in the lecture. After choosing the question that will be asked, the question pops up on every attendee's screen. The prompt includes the question text, and the possible answers. After all of the students have answered the question, or after a set amount of time, the presenter can choose to grade the question. Upon a presenter grading a question, a graph appears showing the user the correct answer and the answer distribution of the class. This provides the presenter instant feedback on the classes overall understanding of the subject matter at hand. These quiz results are also available to be downloaded at the presenters convenience and may be used to replace other methods of in-class quizzes.

Perhaps the most helpful feature of QizBox is that all previous lectures are archived within the system for future reference. This allows students to go back view all the slides, chat, questions, answers, quizzes, and notes from any previous lecture. This ability is extremely helpful when a student needs to study information from earlier in the class. Being able to view previous class discussions and notes at the click of a mouse dramatically increases a student's opportunity to retain the information presented during a lecture.

QizBox also includes a feature that allows presenters the ability to give awards to students. These awards can be given for any reason specified by the presenter. However, the problem with the current award system is two-fold. First of all, as shown by a study that polled users of this system, it was voted by a vast majority of students to be the least useful feature (Hordemann \& Chao, 2012). Secondly, many presenters who use the system find it undesirable to use the current awards system. This stems from the amount of time it takes to issue an award, and that it detracts from the overall lecture timing and delivery to give an award to a student. These two factors combined made it clear that this feature must be reworked for it to play a positive role in the system and served as motivation for our current research.

\section{Considerations for Implementation}

There are many considerations that were necessary for us to keep in mind when implementing our system. The first is how QizBox will provide us a way to properly measure what effects our system has. QizBox is used in over a dozen classes each semester and by hundreds of students in those classes. This provides us with a very large potential for collecting data. The more data collected, the more accurate the conclusions we will be able to draw based on the data. Being able to draw accurate conclusions of the effects of our system is key to understanding the effects that gamification can have, and QizBox provides us with the ability to do so.

The next consideration is how to motivate students to engage in the system using the various methods of gamification. Karl Kapp (2010) points to two separate types of motivation for such a system. First, he considers internal motivation, which consists of challenge, curiosity, and control. Challenge is defined by goals, performance feedback, uncertain outcomes, and self-esteem. Curiosity is defined by sensory and cognitive inquisitiveness and control is defined by choice and power. Secondly, he points to interpersonal motivation, consisting of cooperation, competition, and recognition. Cooperation is defined by users working together to achieve in-game goals. 
Competition is users competing against each other to achieve in-game goals. Recognition is the action of making a user's hard work and mastery visible to others within the system. Our challenge was to design a system that would trigger the greatest number of these motivational aspects while impacting the usability of the system as little as possible.

Finally, a very important consideration is the approach being used to implement the changes to the system. We have chosen to use Agile software development methodology, which is a broad term for development methods based on adaptive planning, flexibility, and iterative development. Older, more traditional methods, tend to concentrate more on comprehensive documentation and a step-by-step plan. Agile development, in contrast, focuses on developing working software early in the process, adding features over time-boxed iterations, and collaborating with clients frequently throughout the entire development process. This is a methodology that is taught at BGSU and one that the BGSU student developers get hands-on experience with. Implementing this methodology to develop and add gamification to a deployed system, servicing many users, proves to be extremely useful. It allows us to implement each feature individually in its own separate iteration. By doing so, we are able to fully test each individual module prior to building the next. This step-by-step approach is very helpful when making changes to an existing system. Adding a feature completely prior to moving on to another, allows us to minimize any negative effects on the existing system and quickly identify the source of any possible issues.

\section{Our Gamified System}

The gamified system developed for QizBox has three parts. First, we decided on an experience point (XP), level based progression system similar to the system developed by Gåsland in the earlier mentioned research study. Our system, however, instead of being based on generic experience points, is based on five specializations in which a student can gain XP (see Figure 2). This will help to encourage five separate types of behaviors we identified in users of the system; social, intelligent, helpful, inquisitive, and hardworking. Many games employ similar systems as they allow users to have a sense of freedom and an ability to customize their experience within the system to their own personality.

We chose this as a starting point for our system because it will allow for not only some level of personal meaning for the users, but also a feeling of autonomy, both of which, as mentioned earlier, are vital factors in a well gamified system. To implement this, we have associated the normal actions a student would perform with corresponding amounts of XP, and by setting larger amounts of XP needed to attain higher levels this will serve to answer the challenge portion of Kapp's internal motivation. Determining the proper amounts and types of XP to be awarded for specific actions is crucial to having users appreciate the system. By studying in depth the previous usage of the system we were able to determine the average behavior of certain types of users and we calculated the XP for different actions accordingly. To allow for any large changes in user behavior due to our changes we have made the amounts of XP awarded easy to adjust based of future usage data.

Proper implementation of these features will also answer the curiosity and control aspects of Kapp's internal motivation. Not explicitly telling the student how much XP he or she gets for performing actions, and the fact that most actions can give at least small amounts of XP in a specialization outside of what a student might generally expect, will stimulate inquisitiveness in the user as to how their performance in a lecture is evaluated by the system. Such curiosity could lead to students participating in different aspects of the lecture, resulting in students getting a more well-rounded educational experience. Giving a student multiple specializations for them to level up in will stimulate a sense of control over the system and a sense of creating their own method of interacting with the system. By not being told by someone the way in which they are to use the system, a user can feel free to participate in the educational experience in whatever way they 
see fit and still feel like they are an active part of the lecture and the overall classroom experience. For instance, if one user tends to be more social and enjoys discussing in class material in the chat room, that user will be able to do so and still reap the benefits of the gamified system, just as a user who might not be as social, but enjoys taking thorough notes and studying the material in relative seclusion can do the same thing.

Secondly, we decided to add an achievement system similar to that found in Foursquare (see Figures 2 and 3). This system gives badges for performing the tasks required of an engaged student during a lecture. The achievement system will grant badges for a large variety of actions, whether it be the basic actions that a student would perform during a lecture (i.e. taking notes or answering a quiz question), or some more seldom occurring actions that would only be performed by a student who is truly engaged in the lecture and participating actively in it.

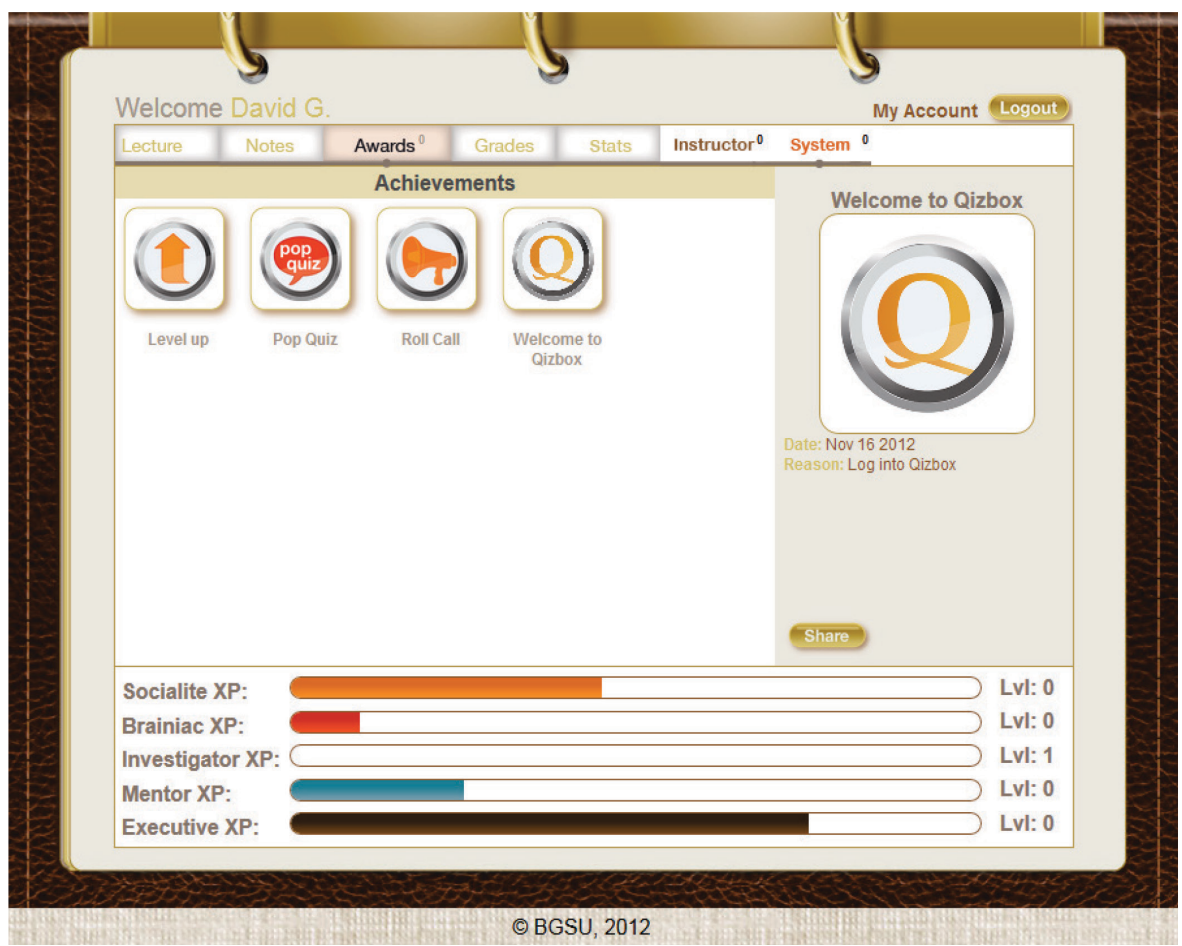

Figure 2. Awards page showing a users achievements and current levels 


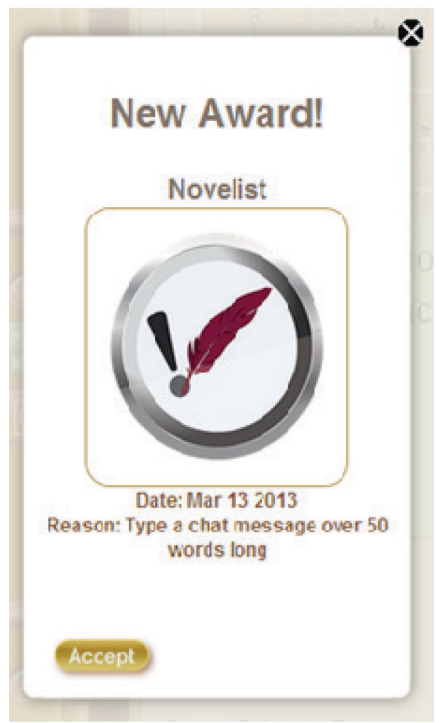

Figure 3. Acheivement pop-up

The badges formerly awarded by the presenter have also been modified to grant XP based on one of the areas of specialization. The presenter may bring up the roster at any time and select the student or students deserving of an award. There are three types of badges, presented graphically by a thumbs-up symbol, a trophy, and a star. Each badge is offered in bronze, silver, and gold (see Figure 4) and each has a specific and corresponding value in XP. The appropriate badge is determined by the presenter, who may also choose what specialization to award the badge for. As pictured below, a key is provided to help the presenter determine this award.
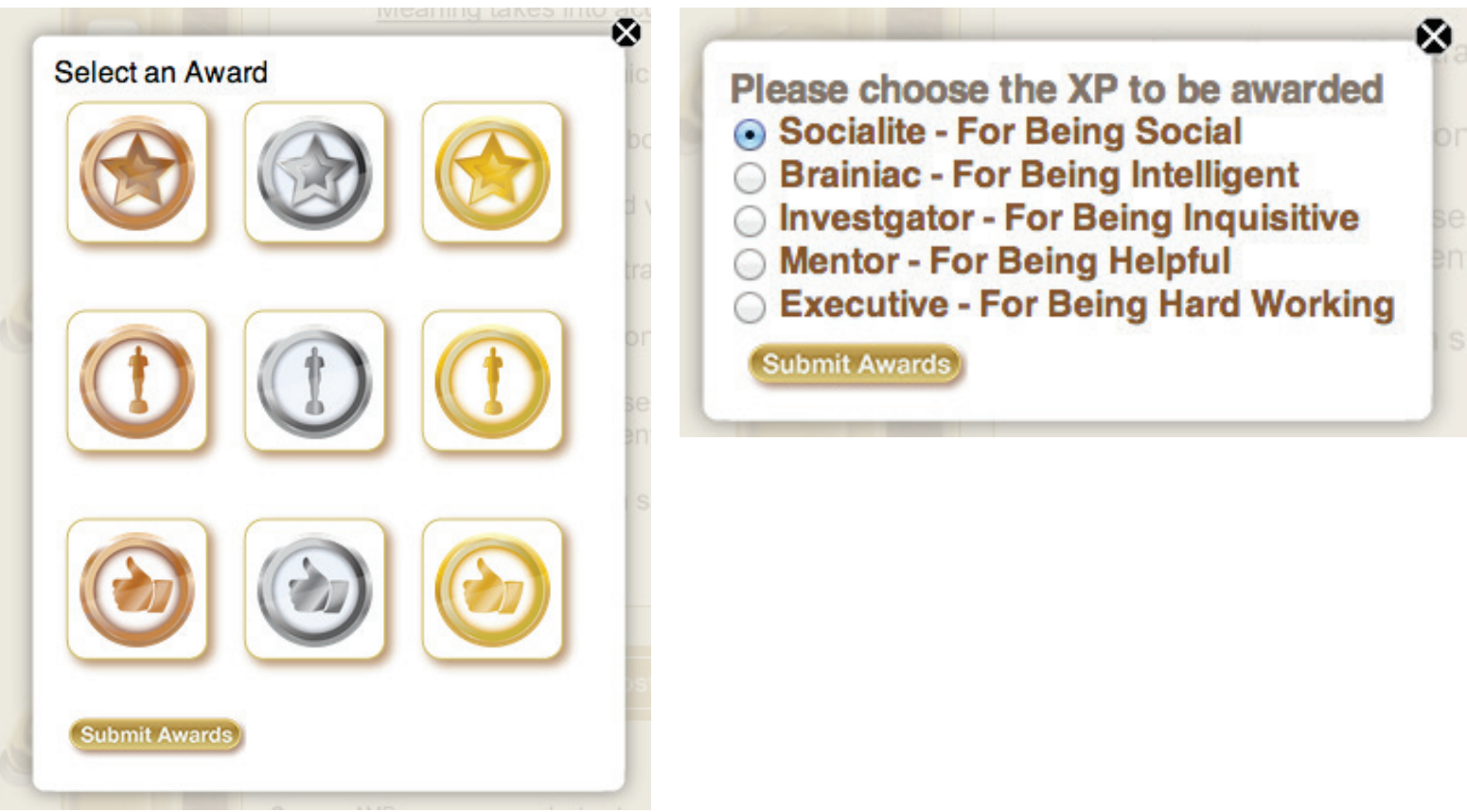

Figure 4. Presenter awards and XP key

Providing badges awarded by either the system or the presenter meets the goal of mastery that Deterding (2011) and Kim (2011) both state as being a requirement of any system that intends to 
use gamification to encourage engagement. Giving a user positive feedback in the form of badges when they achieve certain goals will foster a feeling of accomplishment in the user. These feelings achieved by the perceived mastery of a system, will encourage further effort to gain higher levels of mastery. Furthermore, by making these so that they are publicly displayable to other users of the system, we hope to trigger the recognition and competition aspects of Kapp's interpersonal motivation. By giving a student a tangible, public, representation of work done in the system they gain recognition for those actions from their peers, and, therefore, in certain types of students, this will trigger a feeling of competition, to achieve the highest achievements possible. Both of these facts, as shown by the success of Foursquare and other similar applications, are extremely useful in motivating users of an otherwise non-motivating system.

Lastly, we developed an idea to give students who gain levels in a particular specialization the ability to assist their fellow students in gaining XP at a faster rate in that specialization by granting them a temporary 'buff', or XP amplifier. This is an idea we developed to answer what we believed to be a small gap in the motivational ability of the other two parts of our system. That gap covers Kapp's final aspect of motivation, that being cooperation. There is no doubt that being able to cooperate with other users of a system is something that drives many individuals to be motivated to use that system. Our challenge was to find a way to use the motivational power of cooperation to motivate the proper actions from our users.

There are a couple ways in which this particular design encourages the type of actions from users that will be beneficial for students in a learning environment. First of all, by requiring users to level up in a specialization prior to being able to grant a buff, it further motivates a user to achieve mastery in the system. Beyond that, however, there is a much more useful motivational aspect to this part of the system, that being that it encourages cooperation, not between students that excel in the same specialization, but different specializations. This will encourage students to interact with other students who engage with learning in a different way than they themselves do, and in turn lead to students gaining a more diverse view of their education, and ideally, more interest in learning as a whole.

This combination of features comprises a system that we believe offers the best opportunity to engage the largest number of students. Evaluating many aspects considered by experts to be vital to effective gamification and creating mechanics to simulate every aspect of motivation were key factors to designing our system.

During implementation, emphasis has been put on making these changes as seamless and intuitive as possible to allow users to utilize the new features without requiring any out of the ordinary action from them. During a lecture, the system automatically keeps track of a student's actions, resulting XP, levels reached, and achievements earned. This allows students to use the system in the same way they did prior to gamification but with the added functionality and feedback available for them at any time. This should result in minimal changes in the way a lecture is perceived, by either a student or presenter, except perhaps for increased student participation.

\section{Future Research}

At the time of this publication, we have completed implementation of our gamified system. The newly gamified version of QizBox is being used in over a dozen classrooms at Bowling Green State University and other Universities. Our next challenge will be to map user behavior, gain firsthand user feedback after using the system, and determine what actual effects our new system has had.

The methods of doing this will be varied. Viewing data from archived lectures will provide us with data that shows us student actions within the lecture. Sitting in on lectures that use QizBox will provide us with useful information, as well. We will, by doing so, be able to see how Qiz- 
Box, and more specifically the gamified changes, affect the actual in-classroom experience. Surveying users will also be an important factor in determining the system's effects. Asking a user their direct feelings about the system provides information that is impossible to acquire by any other means. These methods, will allow us to compare user actions and opinions of our gamified system to data we have collected on the previous versions of QizBox. This comparison will provide us with valuable data that we will be able to use to understand what effect our gamification has had and if any changes can be made to further improve the system.

We truly believe, as many do, that the power of games is tremendous. We also believe that working on bringing that power into non-gaming contexts is not only worthwhile, but something that, when done correctly, can impact many lives in helpful and positive manner. Research in this area will undoubtedly continue to grow in the coming years as gamification continues to gain traction. We hope that our work can contribute to finding useful and unique ways of using gamification to further efforts in education and other fields.

\section{References}

Chao, J., Parker, K., \& Fontana, A. (2011). Developing an interactive social media based learning environment. Issues in Informing Science and Information Technology, 8, 323-334.

Cheng, R., \& J. Vassileva. (2005). Adaptive reward mechanism for sustainable online learning community. Proceedings of the 2005 Conference on Artificial Intelligence in Education: Supporting Learning through Intelligent and Socially Informed Technology. Amsterdam, The Netherlands. pp. 152-159.

Deterding, S. (2011). Meaningful play: Getting gamification right. Retrieved from http://www.youtube.com/watch?v=7ZGCPap7GkY

Deterding, S., Dixon, D., Khaled, R., \& Nacke, L. (2011). From game design elements to gamefulness: Defining "gamification". MindTrek'11 Proceedings of the 15th International Academic MindTrek Conference: Envisioning Future Media Environments. 2011. 9-15.

Gåsland, M. (2011). Game mechanic based e-learning. Master of Science in Computer Science Norwegian University of Science and Technology.

Groh, F. (2012). Gamification: State of the art definition and utilization. Research Trends in Media Informatics. Institute of Media Informatics Ulm University.

Hordemann, G., \& Chao, J. (2012). Design and implementation challenges to an interactive social media based learning environment. Interdisciplinary Journal of Information, Knowledge, and Management, 7, 91-107.

Kapp, K. L. (2010). The gamification of learning and instruction. San Francisco, CA: Pfeiffer.

Kim, A. J. (2011). Smart gamification: Seven core concepts for creating compelling experiences. Retrieved from http://www.youtube.com/watch?v=F4YP-hGZTuA

Lee, J. J., \& Hammer, J. (2011). Gamification in education: What, how, why bother? Academic Exchange Quarterly, 15(2).

Locke, E. A. (1991). Goal theory vs. control theory: Contrasting approaches to understanding work motivation. Motivation and Emotion, 15(1), 9-28.

McGonigal, J. (2010). Gaming can make a better world. Retrieved from www.youtube.com/watch? $v=$ dE1DuBesGYM

Montola, M., Nummenmaa, T., Lucero, A., Boberg, M., \& Korhonen, H. (2009). Applying game achievement systems to enhance user experience in a photo sharing service. MindTrek '09. 2009. 94-97.

O'Brien, H. L., \& Toms, E. G. (2008). What is user engagement? A conceptual framework for defining user engagement with technology. Journal of the American Society for Information Science \& Technology, 59(6), 938-955. 
Raymer, R. (2011). Gamification: Using game mechanics to enhance e-learning. eLearn Magazine. Retrieved from http://elearnmag.acm.org/featured.cfm?aid=2031772

Sicart, M. (2008). Defining game mechanics. Game Studies, 8(2).

Zichermann, G., \& C. Cunningham. (2011). Gamification by design. (Ed. Mary Treseler. 1st ed.) Sebastopol, CA: O'Reilly Media.

\section{Biographies}

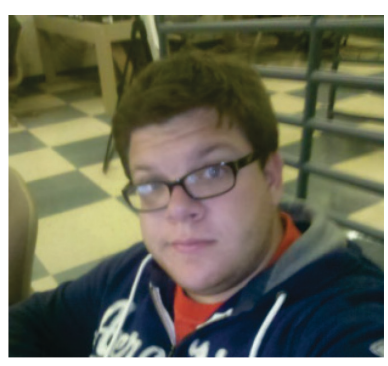

David Giannetto is a Software Engineer at Agile Oasis Technologies in Bowling Green, Ohio who graduated summa cum laude with a B.S. in Computer Science from Bowling Green State University in December 2012. He has $2+$ years of professional experience in the software development field with the majority of that being in web based applications. While employed at the Agile Software Factory during his time at BGSU, in the summer of 2012, David received a grant from the BGSU SETGO program to fund his research on the topic of gamification in education.

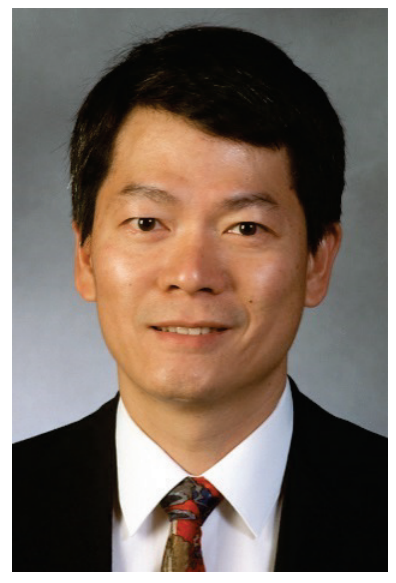

Dr. Joseph T. Chao is an Associate Professor and the Director of the Agile Software Factory in the Department of Computer Science at Bowling Green State University. The Software Factory, which he founded in 2008 with a grant from the Agile Alliance, provides students with service-learning opportunities and real-world project experience in software engineering. Prior to entering academia, Dr. Chao gained more than seven years of industry experience working as Software Engineer, System Analyst, QA Tester, Project Manager as well as Director of Software Development. His research focus is on software engineering with special interests in agile software development, database management systems, web and mobile technologies, and objectoriented analysis and design. Dr. Chao holds an M.S. in Operations Research from Case Western Reserve University and a Ph.D. in Industrial and Systems Engineering from The Ohio State University.

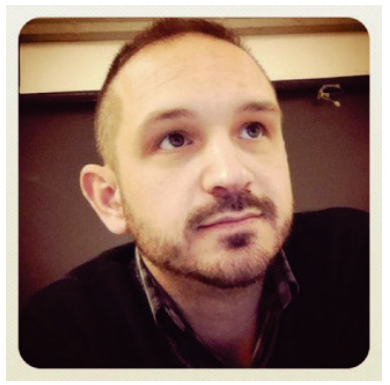

Anthony Fontana is a Learning Technologist and an Instructor of Art at Bowling Green State University in Ohio. Anthony's pedagogical research involves the importance of play or divergent methodologies in the classroom, integrative teaching strategies, and educational technology applications that optimize learning outcomes by providing channels of content transfer most familiar to the student. 